\title{
Pinturas de Salvador Dalí para introduzir conceitos de Mecânica Quântica no Ensino Médio ${ }^{+*}$
}

\author{
Rúbia de Fátima Antunes Martins Fernandes ${ }^{1}$ \\ Flaviston Ferreira Pires ${ }^{2}$ \\ Thaís Cyrino de Mello Forato ${ }^{3}$ \\ José Alves da Silva 4 \\ Departamento de Ciências Exatas e da Terra - Setor de Educação em Ciências \\ Universidade Federal de São Paulo \\ Diadema - SP
}

\section{Resumo}

Poucos trabalhos têm apresentado resultados do ensino de mecânica quântica no ensino médio. Como um alto nível de abstração é exigido, é necessário reconsiderar os pressupostos teóricos, abordagens e metodologias, a fim de reduzir as dificuldades na sua inserção. Este artigo apresenta os resultados de uma pesquisa, que é uma proposta didática para ensino médio compreendendo discussões sobre mecânica quântica e elementos que relacionam física e algumas pinturas de Salvador Dalí. Abraçar as relações entre a física e a arte nos permite aproximar e expressar as relações entre a educação científica e a cultura, com formas alternativas para enriquecer o significado do conhecimento, também buscando proporcionar aos alunos uma visão mais ampla sobre a construção do conhecimento científico, em um diálogo inteligente com o mundo. Para isso, a proposta apresenta uma metodologia operatória, aproximando a ciência como conhecimento histórico e social para ensinar mecânica quântica, e visa tornar o aluno capaz de desenvolver hipóteses, conceitos, situar explicações científicas no tempo, em suma, operar de acordo com as ferramentas fornecidas. Trabalhar com as formas pelas quais a física,

\footnotetext{
+ Salvador Dalí's paintings to introduce Quantum Mechanics concepts in High School

* Recebido: outubro de 2016. Aceito: fevereiro de 2017.

${ }^{1}$ E-mail: rubia.fernandes95@gmail.com

2 E-mail: ton.fpires@hotmail.com

3 E-mail: thaiscmf@gmail.com

${ }^{4}$ E-mail: josealves.unifesp@gmail.com
} 
introduzida como um componente cultural, influencia as interpretações dos fenômenos macro e microscópicos contribui para a compreensão da física moderna, parte da física do século XX. Portanto, adicionar elementos culturais ao mundo da física parece ser cada vez mais necessário, uma vez que parece ressignificá-la ao reumanizar seu conhecimento. Além disso, usar o contexto histórico parece nos dar uma maior amplitude ao conhecimento, uma vez que ele também começa a fazer parte de uma cultura mais ampla, além de seu significado científico.

Palavras-chave: Salvador Dalí; Mecânica Quântica; Ensino de Física; Ensino Médio.

\begin{abstract}
A few papers have presented results of teaching Quantum Mechanics in High School. As a high abstraction level is demanded, it is necessary to reconsider theoretical assumptions, approaches and methodologies, in order to reduce difficulties in its insertion. This paper presents the achievements of a research, which is a didactic proposal for High School comprising discussions about Quantum Mechanics, involving elements that relate Physics and some paintings of Salvador Dali. Embracing the relations between Physics and Art allows us to approach and express the relations between scientific education and culture with alternative ways to enrich the knowledge meaning, also aiming to provide students with a broader view about the scientific knowledge construction in an intelligent dialogue with the world. To do so, the proposal presents an operative methodology, approaching science as a historical and social knowledge to teach quantum mechanics, and it aims to make the student able to hypothesize, conceptualize, situate scientific explanations in time, in short, operate according to the provided tools. Working with the ways in which Physics, introduced as a cultural component, the interpretations of macro and microscopic phenomena and contributes to the understanding of Modern Physics, part of twentieth-century Physics. Therefore, adding cultural elements to Physics world seems to be increasingly necessary, as it seems to resignify it by rehumanizing its knowledge. In addition, using the historical context seems to give us a greater extensiveness to knowledge, since it also starts being part of a broader culture, beyond its scientific meaning.
\end{abstract}


Keywords: Salvador Dalí; Quantum Mechanics; Physics Teaching; High School.

\section{Por que trabalhar com Física e Arte?}

Construir caminhos que explicitem as relações entre as diversas vertentes da cultura humana, como as diferentes linguagens, os padrões sociais, o conhecimento científico e as artes, nem sempre é tarefa fácil. As diferentes interfaces que compõem a construção cultural de uma determinada época nem sempre apresentam, claramente, pontos de convergência.

As ciências exatas são frequentemente atribuídas a um caráter meramente teórico e experimental excluindo, por exemplo, espaços de contemplação da natureza, mesmo que esta seja seu objeto de estudo. Num primeiro olhar, essas ciências, dentre as quais destacamos a física, são tratadas como distantes das artes, de caráter criativo em que a contemplação da natureza está intimamente relacionada. Nesse sentido, no século XVIII, o filósofo alemão Georg W. F. Hegel (1770-1831) formulou uma distinção entre as culturas científicas e artísticas, defendendo a ideia de que a contemplação da beleza e suas consequências estéticas estão diretamente relacionadas à filosofia da arte, sendo essa privilegiada em detrimento do conhecimento científico (HEGEL, [1820-1829] 1996).

Em contraposição à concepção hegeliana, entretanto, o filósofo prussiano Immanuel Kant (1724-1804) acreditava que a noção de belo se dá a partir da contemplação que um indivíduo faz de determinado objeto e, por meio desta contemplação, este indivíduo pode intuir e refletir sobre o que está a contemplar. O mesmo é válido para o contexto científico, em que nenhuma teoria natural é formulada de forma isolada, dependendo sempre de quem está a contemplar a natureza, bem como das hipóteses e questões estéticas internas que este indivíduo traz consigo (KANT, [1790] 1993).

Há historiadores que defendem esse movimento de separação entre a arte e a ciência, como intrínseco ao seu processo de institucionalização, culminando com as especializações científicas no século XIX (ALFONSO-GOLDFARB, 1994). Há, também, quem defenda que a afirmação de independência das ciências, com o ganho de autonomia, cause um desligamento do velho tronco comum aos diversos ramos filosóficos, no sentido de que o movimento de separação entre áreas de conhecimento, aparentemente diferentes, cause prejuízo para todos os lados (DE BROGLIE; SERTILLANGES, [1942] 1955).

Embora ideias opostas, como as de Hegel e Kant, por exemplo, tenham nutrido uma visão dicotômica por quase dois séculos, em meados do século XX alguns pensadores iniciaram um movimento de problematização dessa interpretação sobre os olhares para a natureza. Esse é o caso de Snow ([1959], 1993), que defende que a polarização entre as culturas artística e científica estava conduzindo à fragmentação do conhecimento humano e sugere que este impasse só poderia ser resolvido por meio de uma terceira cultura, sendo esta a ponte entre a razão e a emoção, assim representando a unificação do conhecimento. 
Atualmente, percebemos que a elaboração do conhecimento científico não se resume apenas às teorias, experimentos, fórmulas e números, cabendo, também, o caráter estético e contemplativo, uma vez que há importância da estética dentro da descrição das teorias e modelos científicos (PIRES; SILVA, 2015; MENEZES, 2005), não limitando a estética científica somente ao que os resultados numéricos e experimentais transmitem.

Ao aprofundarmos o olhar sobre ambas as culturas, em muitos momentos históricos, notamos que as concepções artísticas e científicas se mostraram claramente convergentes "levando a interpretações semelhantes a respeito do funcionamento do universo" (REIS; GUERRA; BRAGA, 2006, p. 72), com ambos os protagonistas - artistas e cientistas - podendo representar e perceber o mundo da mesma maneira, porém utilizando diferentes linguagens para sua representação.

Mesmo que, a princípio, física e arte não mostrem um diálogo claro, elas podem ser relacionadas por meio de uma visão abrangente a respeito do processo de construção do conhecimento, que possui um forte elemento cultural, mais especificamente no que tange à discussão sobre conceitos físicos referentes à mecânica quântica. Assim, discutir as relações entre arte e ciência pode possibilitar discussões promissoras sobre as perspectivas de cada uma dessas áreas, podendo extrapolar "o passo inicial [da] pré-abstração, referente à introdução de novos conceitos" (ALCANTARA; JARDIM, 2014, p. 165).

Essa relação pode ser inserida dentro do processo de aprendizagem escolar. De acordo com Menezes e Hosoume (1997), a escolha por essa visão do aprendizado da física

\section{[...] não é uma opção pela superficialidade, pela 'cultura de almanaque'. Pelo con- trário, é uma tentativa de dar aos estudantes uma ideia da ciência e da tecnologia, como parte da cultura, como visão de mundo, e também da cultura da produção e dos serviços da atualidade. Não se trata só de ancorar o desenvolvimento abstrato em exemplos concretos, vividos, do cotidiano do aluno. Trata-se de desenvolver uma sis- temática de reflexão e aprendizado, que transcenda as paredes da escola, que instrua o olhar e o pensar na rua, em casa e no trabalho (MENEZES; HOSOUME, 1997, p. 28 apud BROCKINGTON, 2005, p. 11).}

Alguns autores, assim como os Parâmetros Curriculares Nacionais (PCN) e os Parâmetros Curriculares Nacionais+ $(\mathrm{PCN}+)$, apontam a necessidade de contextualização históricosocial do conhecimento científico. Eles têm evidenciado a relevância do papel desempenhado pela História e Filosofia da Ciência (HFC) ${ }^{5}$ no ensino e aprendizagem das ciências, bem como

\footnotetext{
${ }^{5} \mathrm{O}$ acrônimo HFC, ou em inglês HPS (History and Philosophy of Science), tem sido utilizado por diversos autores, desde a década de 1990, com o pressuposto de que abordagens históricas permitem exemplificar e explicitar aspectos epistemológicos do desenvolvimento das ciências, ou seja, promovendo discussões no âmbito da filosofia. A revista "Science and Education", fundada por Michael Matthews, em 1992, foi um dos principais veículos onde esse enfoque para HFC foi se tornando internacionalmente mais conhecido e que foi sendo apropriado pela comunidade de pesquisadores na interface desses campos com o Ensino de Ciências. Atualmente, alguns autores inserem discussões no âmbito da Sociologia da Ciência, acrescentando um "S" ao acrônimo (HFSC), enquanto alguns deles mantém HFC. Há os que também adotam apenas HC (história das ciências), em geral historiadores das ciências, por entenderem que a abordagem histórica em perspectiva historiográfica atual supõe que narrativas dos recortes
} 
a importância de sua inclusão nos currículos sem, no entanto, criar uma disciplina específica ou incluir tópicos de HFC de forma explícita, propondo a utilização de elementos significativos ao ensino. Assim, a HFC pode ser pensada como "estratégia didática facilitadora na compreensão de conceitos, modelos e teorias" (MARTINS, 2007, p. 127), tornando possível o trabalho com aspectos relevantes da Natureza das Ciências (NdC) em salas de aula. No entanto, neste sentido, é importante enfatizar que cada episódio histórico exemplifica ou faz emergir aspectos distintos da NdC, uma vez que estes são intrínsecos à cada cultura e época (ACEVEDO-DÍAS; GARCÍA-CARMONA, 2016; BAGDONAS, 2015).

Discutir aspectos da história das ciências é, portanto, discutir a história da própria humanidade e, dessa forma, é bastante positivo também considerar a história das artes, uma vez que esta é parte do conhecimento de uma determinada cultura e em uma determinada época apenas utilizando diferentes linguagens.

\section{Salvador Dalí e a Mecânica Quântica: em busca da ponte entre as duas culturas}

De acordo com Carme Ruiz (2010), do Centro de Estudios Dalinianos da Fundación Gala-Salvador Dalí (Espanha), Salvador Dalí (1904-1989) foi um pintor espanhol (catalão) surrealista que desde cedo, quando ainda era adolescente, construiu sua relação com as ciências, demonstrando grande interesse pela leitura de artigos científicos.

O movimento surrealista, fundado por André Breton em 1924 e seguido por Dalí, foi um movimento de ideias, de criação e de ação artística que, dentre outras vertentes, também foi influenciado pela física moderna, desenvolvida nos dez anos anteriores e que se tornaria um elemento chave nas obras de Dalí durante a década de 1930 (RUIZ, 2010). De acordo com a autora, foram os surrealistas que submergiram Dalí no mundo da física. Para o pintor, a nova realidade proposta pela recente teoria da relatividade de Albert Einstein (1879-1955), seguida pelas teorias da física quântica pareciam extraordinárias (idem, ibidem).

Salvador Dalí, inclusive, assumiu um alter ego com o mesmo sobrenome do físico alemão Werner Heisenberg (1901-1976). Nas palavras do próprio pintor: "No período surrealista, eu queria criar a iconografia do mundo interior, o mundo do meu admirável pai Freud. Eu me sai bem nisso. Hoje o mundo exterior - aquele da física - transcendeu o da psicologia. Meu pai hoje é o Dr. Heisenberg” (DALÍ, 1959, tradução livre).

A biblioteca do pintor refletia sua paixão de maneira clara, contendo aproximadamente uma centena de livros (os quais continham notas e comentários nas margens) sobre vários temas científicos, dentre os quais se destacavam a física clássica, a mecânica quântica, origens da vida, evolução e matemática, bem como muitas revistas que Dalí assinava para se manter atualizado sobre as novidades científicas (RUIZ, 2010).

históricos explicitem, em maior ou menor intensidade, os seus aspectos epistemológicos e contextuais (FORATO, 2008). Neste trabalho, seguiremos a tradição de Matthews (1994) e André Martins (2007), dentre outros, e manteremos HFC. 
Carme Ruiz (2010) afirma que, ao seguir o trabalho de Salvador Dalí, podemos atravessar um período importante da ciência do século XX, ao menos no que diz respeito aos avanços científicos que particularmente o afetavam.

Atualmente, as obras de Dalí podem, ainda, ser utilizadas como ferramenta de reflexão mais profunda "das relações entre 'diferentes' áreas do conhecimento e seu significado" (ALCANTARA; JARDIM, 2014, p. 165), permitindo "uma aproximação entre educação científica e cultura, externando alternativas para se discutir os valores culturais e disciplinares do conhecimento científico, enriquecendo o significado do mesmo" (idem, ibidem, p. 165-6).

A utilização das obras de Dalí apresenta possibilidades para tratar de temas referentes à Física Moderna e Contemporânea (FMC), mais especificamente, neste caso, no que tange à mecânica quântica, de forma conceitual e sem a necessidade de apresentar aplicações diretas no cotidiano dos estudantes. Segundo Brockington (2005, p. 20),

\footnotetext{
como muito dos temas de FMC não têm uma aplicação direta, pode-se trabalhar mais essa dimensão "contemplativa", prazerosa do conhecimento, focando os processos da ciência, suas motivações, seus problemas e questionamentos. Assim, pode-se discutir questões fundamentais da construção das teorias e suas relações com a realidade, na tentativa de desenvolver nos alunos a satisfação intelectual que se tem ao compreender esses assuntos.
}

Nesse contexto, entendendo a física como parte do processo de construção da sociedade, afetando e sendo afetada por outras áreas, se faz necessário que a escola promova um trabalho interdisciplinar que permita uma aproximação entre as duas culturas de forma a possibilitar um diálogo inteligente com o mundo (SNOW, [1959] 1993), formando cidadãos que não só se apropriem dos conhecimentos científicos, mas que também se tornem aptos a contemplar a beleza contida neles, assim como acontece no caso das artes.

A proposição de um ensino que promova também a contemplação de aspectos estéticos da física, seu diálogo com outras áreas do conhecimento, não limitaria seu ensino a converter todo o conhecimento científico em conhecimento necessariamente prático, podendo atuar, então, como um novo tipo de motivação. Não excluímos, aqui, a necessidade de contextualização do conhecimento da física reconhecida no cotidiano do aluno (MENEZES, 2005). Pelo contrário, acreditamos que os aspectos estéticos e sociais contribuirão com um saber que promova, também, sua interação mais crítica com o mundo.

Ao adentrar a esfera de outras dimensões do conhecimento científico, como o conhecimento teórico e conceitual, o aprendizado aconteceria, portanto, meramente pelo prazer de aprender, sem motivações diferentes dessa, sem a obrigatoriedade da utilidade no cotidiano do aluno. Ao apoderar-se de um conhecimento cultural, os estudantes podem, também, apreciar os conhecimentos dos conceitos físicos, uma vez que a física passa a ser parte da cultura (BROCKINGTON, 2005; ZANETIC, 1989).

Acreditamos que a concepção de mecânica quântica adotada por Salvador Dalí tenha sido convergente com a interpretação dualista realista que, de acordo com Pessoa Jr (2003), foi 
formulada originalmente por Louis de Broglie (1892-1987), e também proposta por David Bohm (1917-1992). Segundo esta interpretação

o objeto quântico se divide em duas partes: uma partícula com trajetória bem definida
(mas desconhecida), e uma onda associada. A probabilidade da partícula se propa-
gar em uma certa direção depende da amplitude da onda associada, de forma que em
regiões onde as ondas se cancelam, não há partícula. Não há mais contradição por-
que o objeto se divide em duas partes, uma sendo só partícula, e a outra só onda
(PESSOA JR, 2003, p. 5).

Dessa forma, o caráter dualista também pode ser atribuído aos quadros de Dalí utilizados nesta proposta sem que haja contradição entre a ciência e arte, ou prejuízo na discussão conceitual.

\section{A materialização das ideias: uma proposta concreta para sala de aula}

Essa pesquisa teve como finalidade estudar referenciais teóricos e metodológicos que pudessem fundamentar a materialização das ideias acima defendidas, em uma proposta concreta para a sala de aula, numa perspectiva freireana. Longe de buscar soluções prontas ou estratégias pontuais que reduzem o ensino ao método e reconhecendo a pertinência das didáticas específicas das ciências, buscaram-se caminhos para promover uma participação ativa do aluno no seu processo de aprendizado (MOREIRA, 2013). Nesse escopo, considerou-se as contribuições que as abordagens históricas e filosóficas do diálogo entre a física e a arte podem oferecer aos complexos processos de ensino e aprendizagem envolvidos nos conteúdos da física do século XX.

Desse modo, a questão de investigação voltou-se a: como construir uma proposta didática, que inscreva os pressupostos atuais de uma formação crítica e emancipatória, voltada ao aprendizado de conteúdos de mecânica quântica, contextualizados historicamente em diálogo interdisciplinar com a arte? Buscaremos, por meio da explicitação do percurso e dos resultados obtidos, avaliar o quanto as escolhas dos referenciais metodológicos foram adequadas para a construção da proposta.

Assim, ponderando sobre os argumentos anteriormente discutidos, este trabalho pretende apresentar os resultados da pesquisa, bem como o percurso de desenvolvimento de uma proposta didática interdisciplinar envolvendo, majoritariamente, física e arte. Compreendendo que, neste caso, os objetivos da pesquisa e os objetivos da proposta didática estão intimamente conectados/relacionados, sua explicitação favorece a compreensão do percurso metodológico adotado. A escolha dos referenciais teóricos e metodológicos deve levar em conta a concepção de física que se deseja fomentar, e que está refletida nos objetivos pedagógicos pretendidos. Assim, os objetivos da proposta didática são explicitados abaixo.

Pretende-se que as discussões sobre mecânica quântica sejam abrangidas por meio da utilização de algumas obras de Salvador Dalí, contextualizadas com o período histórico em que 
foram pintadas. Dessa forma, os principais objetivos da proposta didática para a sala de aula são:

- Mostrar a construção do conhecimento científico como um processo humano, histórico e social;

- Trabalhar com as formas pelas quais a física influencia as interpretações de mundo;

- Introduzir a física como componente cultural, inclusive, ajudando a moldar a sociedade;

- Compreender os conhecimentos da FMC, mais especificamente sobre mecânica quântica, a partir dos conceitos sobre modelos atômicos, quanta, dualidade onda-partícula e princípio de incerteza de Heisenberg;

- Tornar acessível a física do século XX aos alunos da escola básica, tendo em conta uma educação para os direitos humanos;

- Estimular o uso da argumentação, desenvolver a capacidade leitora e escritora e incentivar a participação em trabalhos em grupo.

\section{Como fizemos a pesquisa}

Esta pesquisa envolveu a prospecção e estudo de referenciais teóricos e metodológicos para fundamentar a elaboração de uma proposta didática para a escola básica, composta por atividades didático-pedagógicas envolvendo quatro temas relacionando obras de Salvador Dalí e mecânica quântica.

Ela se originou durante uma disciplina na formação inicial de professores de física, que busca construir uma prática crítica, reflexiva e transformadora, fundamentada e apoiada pela pesquisa (DEMO, 1996; PIMENTA; GHEDIN, 2012; MOURA, 2012). Procura-se a preparação do professor para

[...] o questionamento reconstrutivo [que] envolve saber procurar material, interpretar e formular, pois [...] é preciso aprender a aprender e esta se caracteriza pelo contraler, reelaborando a argumentação; refazer com linguagem própria, interpretar com autonomia; reescrever criticamente; elaborar texto próprio, experiência própria, formular proposta e contraproposta (DEMO, 1996, p. 29).

Como parte desse processo formativo, os futuros professores debatem questões contemporâneas do ensino de ciências e vivenciam os desafios de elaborar propostas didáticas que perpassam diferentes abordagens e metodologias, sempre pautados em referenciais teóricos atuais.

As discussões entre os pesquisadores, sendo dois licenciandos e dois docentes, ocorreram inicialmente no contexto da disciplina e aprofundaram-se após seu término, ampliando tanto os aportes teóricos quanto a reflexão explícita sobre o processo formativo, bem como o aprofundamento nos conceitos da física, propriamente ditos. 
Todo esse processo foi amparado pela metodologia qualitativa em educação, que visa os pesquisadores "como o seu principal instrumento" (ANDRÉ; LUDKE, 1986, p .10). A escolha dos referenciais teóricos para o desenvolvimento da proposta será descrita na próxima seção.

\section{Como fundamentamos a proposta}

Nossa proposta advinha das aulas de uma disciplina de prática pedagógica de física da Universidade Federal de São Paulo. O projeto consistia na elaboração de uma sequência de aulas que integrasse conhecimentos físicos com arte, para aplicação na educação básica e que favorecesse diferentes compreensões do mundo à nossa volta.

O desenvolvimento da proposta teve início com o estudo das bases teóricas de Reis, Guerra e Braga (2006) e Zanetic (1989; 2006) com o princípio de nortear os licenciandos em questões sobre as relações entre as ciências, mais especificamente a física e a arte, além de realçar formas para a construção de pontes entre as duas culturas. Na sequência, foram realizados os estudos de Gil-Pérez et al. (2001) e Forato et al. (2011), visando a compreensão de que todo discurso ou representação sobre a ciência inscreve uma concepção sobre ela. Assim, os discentes refletiram sobre caminhos para fomentar uma visão de ciência melhor informada epistemologicamente, principalmente, não neutra, sendo trabalhada como uma construção humana, histórica e social (ALLCHIN; ANDERSEN; NIELSEN, 2014). Outro referencial, Alcântara e Jardim (2014), permitiu mais exemplos sobre História e Filosofia da Ciência a partir de representações artísticas. Brockington (2005) ofereceu subsídios no que tange ao uso de simuladores e Modelos na Ciência; e, por fim, Ronca e Terzi (1993) para elucidar sobre possibilidades avaliativas e sobre a construção das aulas que compõem a proposta. Esse último referencial, que foi a base para o desenvolvimento da proposta didática, será apresentado a seguir.

\section{Como fundamentamos as aulas e as avaliações}

As perspectivas sobre educação, inscritas na proposta da prova operatória de Ronca e Terzi (1993) ofereceram as bases para construir as atividades. Por meio dessa metodologia, os autores defendem que existe uma necessidade urgente de que a escola repense seu cotidiano, decidindo se é um lugar onde se constrói e sistematiza o conhecimento ou se é um lugar que transmite conhecimentos "prontos, acabados, inquestionáveis" (RONCA; TERZI, 1993, p. 19); assim como a necessidade de que se repense as avaliações.

Essa proposta de modificação das avaliações se relaciona profundamente com a maneira como o professor encara sua relação com os alunos, com os conteúdos e a aprendizagem, sendo, então, um problema filosófico e metodológico. A ideia por trás está no dilema: “como formar pessoas que pensem, que participem, que argumentem?” (idem, ibidem, p. 20).

Com isso, a avaliação da aprendizagem passaria a ser um momento de reorganização dos conhecimentos, tendo dimensão e metas, analisando se o aluno é capaz de OPERAR os 
conteúdos "a partir da leitura, compreensão e interpretação de questões" (idem, ibidem). A prova "operatória" se caracteriza como um momento onde o aluno pode "viver internamente a construção ou reconstrução de conceitos ao longo do caminho da aprendizagem" (idem, ibidem, p. 25).

A prova operatória pode ser dividida em três partes: i) um determinado tema demandará a expressividade escrita na forma de redação, de forma que o aluno possa apresentar e discutir o tema proposto; ii) proposição de perguntas simples e pequenas, mostrando a importância de determinado conteúdo e a necessidade de conquistar pré-requisitos, inserindo-se "entre a composição, expressividade escrita e a resolução de problemas" (idem, ibidem, p. 36); iii) problemas relacionados ao tema proposto, como a matematização, por exemplo. Dessa maneira, a prova visa ser um momento de profunda reflexão e estudo comprometido com o desenvolvimento global do pensamento. Para sair do impasse imediato no sentido da utilização de determinado conteúdo, o educador deve assegurar que suas aulas, conteúdos e provas se comprometam "mais com o desenvolvimento do pensamento e das operações mentais e menos com a informação enfatizada e isolada em si mesma" (idem, ibidem).

Dada a relação de reflexão entre avaliação e aula, para gerar uma relação causal com a prova operatória, cabe pensar na aula operatória. Essa relação se dá, pois ambas espelham as concepções gerais e particulares que o professor tem de e sobre as ciências, da compreensão do que é o conhecimento e dos caminhos até ele. Aqui, a ideia é conduzir o aluno ao centro do processo. Nesta perspectiva cabe ao professor promover e estimular as operações, colocando-o "muito mais para ensinar a operar do que para simples transmissor de conteúdos" (idem, ibidem, p. 38).

A aula operatória se relaciona mais com a forma de se explicar do que na diminuição do tempo de fala por parte do professor, fazendo com que essa aula possa ser uma aula expositiva, mas não apenas. Ela é problematizada e problematizante, fazendo "surgir uma dose de angústia, de inquietação, de inconformismo perante as ciências" (idem, ibidem, p. 43). Implica, por fim, estender as mãos para caminhar junto aos alunos por um caminho de liberdade, autonomia e independência.

\section{Como desenvolvemos a proposta}

Além das bases teóricas supracitadas, foram debatidos os PCN (BRASIL, 2000) e os PCN+ (BRASIL, 2002), além do Currículo da Secretaria da Educação do Estado de São Paulo (SEE-SP, 2014-2017), de maneira que a proposta elaborada pudesse abranger os temas referentes à terceira série do ensino médio. As discussões deram novas perspectivas de como promover reflexões relacionadas à contextualização sociocultural a fim de que "o conhecimento científico seja compreendido como resultado de uma construção humana, inseridos em um processo histórico e social" (BRASIL, 2002).

A partir daí, nosso foco foi o estudo das relações entre Salvador Dalí e as ciências (RUIZ, 2010), seguindo para as influências da FMC presentes nas obras do pintor (ANDRADE; 
NASCIMENTO; GERMANO, 2007), com ênfase nas relações com a mecânica quântica.

\section{A proposta}

A partir da temática sobre Salvador Dalí e a mecânica quântica, serão tratados conceitos sobre modelos atômicos, quanta, dualidade onda-partícula e princípio de incerteza de Heisenberg, permitindo a contextualização entre os conceitos físicos, os quadros de Dalí e o momento histórico-científico em que foram pintados. A proposta apresenta temas transversais que permeiam todas as etapas, como HFC, Modelos nas Ciências, e Arte Moderna. O quadro abaixo (Quadro 1) apresenta um resumo com os temas, conteúdos, objetivos, e sugestão de recursos e de duração prevista para cada etapa da proposta. Nos Quadros 2, 3, 4 e 5 são descritas as metodologias sugeridas, os aspectos de NdC mobilizados e sugestões de avaliação. As sugestões de leitura para professores encontram-se no Quadro 6.

Salientamos que o tempo previsto é apenas uma sugestão, cabendo ao professor as devidas adaptações durante a implementação da proposta, conforme o contexto escolar.

Sugerimos que, a fim de melhorar a narrativa da proposta, os alunos devam ter estudado anteriormente os conceitos físicos de ondulatória e eletromagnetismo, além de noções de história da primeira metade do século XX, conforme previstos nos documentos oficiais supracitados. Seria recomendado, também, algum conhecimento sobre a história da arte desse período.

As sugestões de recursos materiais também podem ser adaptadas de acordo com o contexto escolar, por exemplo, substituir o uso de computador e projetor por imagens impressas, conforme disponibilidade.

O uso do simulador PhET (Windows) se apresenta como opção para facilitar a visualização dos fenômenos físicos, sem a necessidade de usar o aparato matemático ou experimental, uma vez que "a maioria das experiências de FMC não pode ser feita nos laboratórios escolares” (BROCKINGTON, 2005, p. 12). Ao optar por usá-lo, sugerimos que o professor faça uma discussão sobre a visão de ciência apresentada pelo software, com possíveis deformações ao mostrar uma ciência neutra, linear, objetiva, pronta, que não falha, fomentando o realismo ingênuo, levando o aluno a crer na existência de verdades científicas absolutas (GIL-PÉREZ et al., 2001; FORATO; PIETROCOLA; MARTINS, 2011).

Quadro 1 - Resumo da proposta didática.

\begin{tabular}{|l|l|l|l|l|}
\hline Temas & Conteúdos & Objetivos específicos & $\begin{array}{l}\text { Sugestão de } \\
\text { recursos }\end{array}$ & $\begin{array}{l}\text { Sugestão de } \\
\text { tempo }\end{array}$ \\
\hline $\begin{array}{l}\text { 1 - A desmateriali- } \\
\text { zação do nariz } \\
\text { de Nero. }\end{array}$ & $\begin{array}{l}\text { - Modelos Atô- } \\
\text { micos. }\end{array}$ & $\begin{array}{l}\text { átomo; } \\
\text { - Compreender as forças atômicas } \\
\text { que mantém seus constituintes em }\end{array}$ & & - Projetor. \\
\hline
\end{tabular}




\begin{tabular}{|c|c|c|c|c|}
\hline & & $\begin{array}{l}\text { equilíbrio; } \\
\text { - Contextualizar o domínio do } \\
\text { átomo com a bomba nuclear. }\end{array}$ & & \\
\hline $\begin{array}{l}2 \text { - A desintegração } \\
\text { da persistência da } \\
\text { memória. }\end{array}$ & $\begin{array}{l}\text { - Quanta; } \\
\text { - Corpo Negro. }\end{array}$ & $\begin{array}{l}\text { - Construir o conceito de quanta; } \\
\text { - Compreender a matéria como } \\
\text { sendo formada por átomos; } \\
\text { - Compreender as limitações do } \\
\text { modelo clássico perante resulta- } \\
\text { dos experimentais com corpo ne- } \\
\text { gro; } \\
\text { - Relacionar física com música. }\end{array}$ & $\begin{array}{l}\text { - Simulador } \\
\text { virtual PhET } \\
\text { (Windows); } \\
\text { - Computador; } \\
\text { - Projetor. }\end{array}$ & $\begin{array}{l}-2 \text { aulas de } 50 \\
\text { minutos. }\end{array}$ \\
\hline 3 - Oposição. & $\begin{array}{l}\text { - Dualidade } \\
\text { onda-partícula. }\end{array}$ & $\begin{array}{l}\text { - Compreender a dualidade partí- } \\
\text { cula-onda; } \\
\text { - Relacionar aspectos de } \mathrm{NdC} \mathrm{e} \\
\text { conteúdos históricos. }\end{array}$ & $\begin{array}{l}\text { - Simulador } \\
\text { virtual PhET } \\
\text { (Windows); } \\
\text { - Computador; } \\
\text { - Projetor. }\end{array}$ & $\begin{array}{l}-2 \text { aulas de } 50 \\
\text { minutos. }\end{array}$ \\
\hline $\begin{array}{l}4 \text { - Mercado de es- } \\
\text { cravos com o busto } \\
\text { de Voltaire. }\end{array}$ & $\begin{array}{l}\text { - Princípio de in- } \\
\text { certeza de Hei- } \\
\text { senberg. }\end{array}$ & $\begin{array}{l}\text { - Compreender o princípio de in- } \\
\text { certeza de Heisenberg; } \\
\text { - Conhecer uma narrativa histó- } \\
\text { rica sobre tal conteúdo. }\end{array}$ & $\begin{array}{l}\text { - Computador; } \\
\text { - Projetor. }\end{array}$ & $\begin{array}{l}\text { - } 2 \text { aulas de } 50 \\
\text { minutos. }\end{array}$ \\
\hline
\end{tabular}

\section{Descrição da proposta}

A seguir, descreveremos a proposta mais detalhadamente (Quadros 2, 3, 4 e 5), constando: estratégias metodológicas, possibilidades de questões de $\mathrm{NdC}$ a serem discutidas e a proposta de avaliação de acordo com a prova operatória (RONCA; TERZI, 1993).

Salientamos que sejam tomados os devidos cuidados com as narrativas históricas aparentemente inofensivas - divulgadas na internet ou na mídia não especializada, ou escritas por não especialistas da HFC, de forma romanceada -, pois elas podem transmitir conteúdos de NdC e História da Ciência de forma distorcida, incorrendo em pseudo-história (MARTINS, 2001; FORATO; PIETROCOLA; MARTINS, 2011) ou deformações sobre o trabalho científico (GIL-PÉREZ et al., 2001).

É importante enfatizar que as representações propostas nos quadros de Dalí são, exclusivamente, interpretações do artista e não traduzem o conceito cientifico exato e em sua totalidade. No entanto, o uso de tais analogias científicas (LOPES; MARTINS, 2009) se torna uma ferramenta poderosa para a apresentação e discussão de conceitos abstratos e que transcendem o universo observável. 
Quadro 2 - A desmaterialização do nariz de Nero.

\begin{tabular}{|c|c|c|c|}
\hline QUADRO/AULA & METODOLOGIA & $\begin{array}{l}\text { QUESTÕES DE } \\
\text { NdC }\end{array}$ & $\begin{array}{l}\text { PROPOSTA DE AVALI- } \\
\text { AÇÃO }\end{array}$ \\
\hline $\begin{array}{l}\text { A } \text { desmaterializa- } \\
\text { ção do nariz } \\
\text { de Nero }\end{array}$ & $\begin{array}{l}\text { - Introdução do quadro por meio do } \\
\text { projetor; } \\
\text { - Relembrar quem foi Salvador Dalí } \\
\text { por meio das discussões de surrea- } \\
\text { lismo; } \\
\text { - Questionar se os elementos da } \\
\text { obra teriam relação com a ciência; } \\
\text { - Possibilidade da romã como re- } \\
\text { presentação de um átomo; } \\
\text { - Problematizar a possível represen- } \\
\text { tação de átomo de Dalí. }\end{array}$ & $\begin{array}{l}\text { - Discussão sobre } \\
\text { modelos atômicos, } \\
\text { na perspectiva de } \\
\text { problematizar os er- } \\
\text { ros conceituais de- } \\
\text { correntes de analo- } \\
\text { gias (LOPES e } \\
\text { MARTINS, 2009); } \\
\text { - Discussão sobre } \\
\text { os modelos na ciên- } \\
\text { cia: o que é um mo- } \\
\text { delo na ciência? } \\
\text { (BROCKINGTON, } \\
\text { 2005). }\end{array}$ & $\begin{array}{l}\text { - Reflexão escrita sobre a } \\
\text { aula por meio da seguinte } \\
\text { questão: } \\
\text { "Considere que a estrutura } \\
\text { de concreto que envolve a } \\
\text { romã, no quadro, represente } \\
\text { o domínio da humanidade } \\
\text { sobre as questões atômicas. } \\
\text { Prestando atenção no conte- } \\
\text { údo da obra, relacione um } \\
\text { acontecimento histórico da- } \\
\text { quele período com a pintura } \\
\text { e com as discussões realiza- } \\
\text { das em aula". }\end{array}$ \\
\hline
\end{tabular}

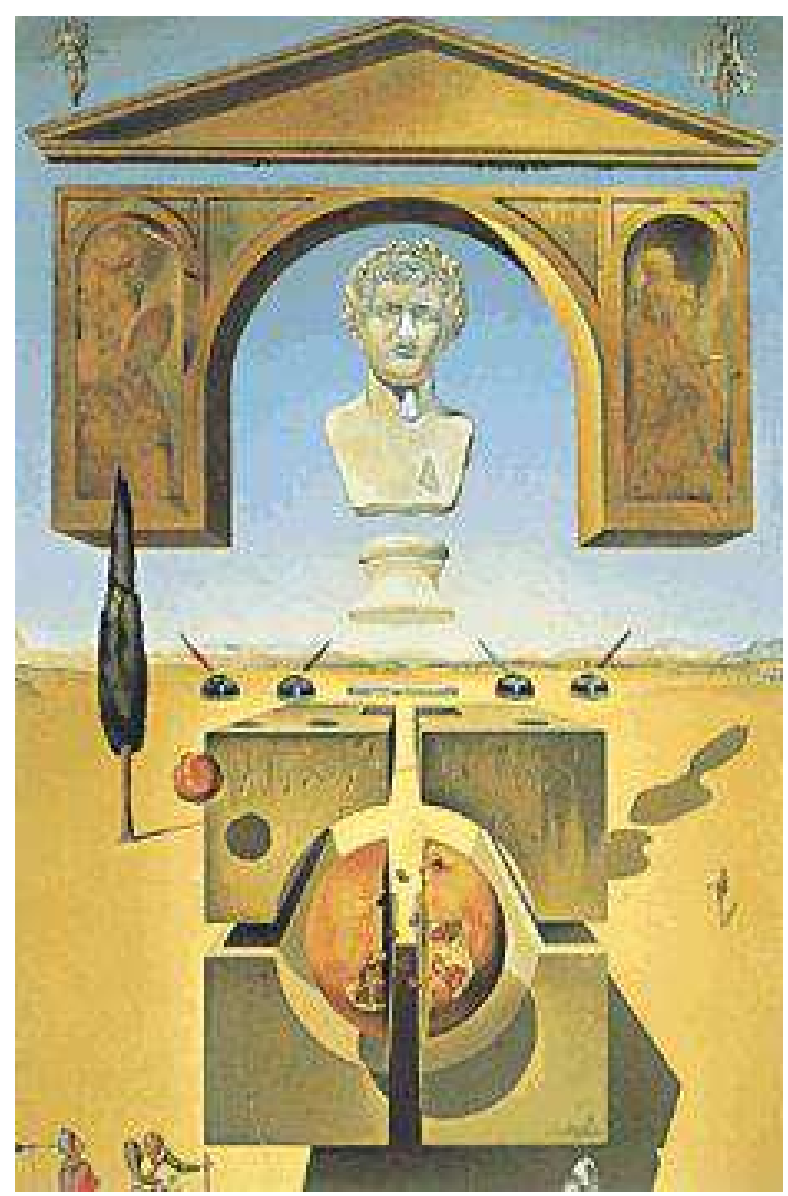

Fig. 1 - A desmaterialização do nariz de Nero. Salvador Dalí (1947). Óleo sobre tela. 76,4 x 46 cm. Fundação Gala-Salvador Dalí, Figueras. 
Quadro 3 - A desintegração da persistência da memória.

\begin{tabular}{|c|c|c|c|}
\hline QUADRO/AULA & METODOLOGIA & $\begin{array}{l}\text { QUESTÕES DE } \\
\text { NdC }\end{array}$ & $\begin{array}{l}\text { PROPOSTA DE AVALI- } \\
\text { AÇÃO }\end{array}$ \\
\hline $\begin{array}{l}\text { A desintegração } \\
\text { da persistência da } \\
\text { memória }\end{array}$ & $\begin{array}{l}\text { - Uso do simulador "Radiação do } \\
\text { Corpo Negro" (PhET): a teoria } \\
\text { clássica não era compatível com re- } \\
\text { sultado experimental da emissão de } \\
\text { corpo negro; } \\
\text { - Apresentação da relação E = h.f } \\
\text { proposta por Planck; } \\
\text { - Apresentação do quadro: i) quanta } \\
\text { como pacotes de energia; ii) outros } \\
\text { elementos do quadro: mísseis atô- } \\
\text { micos, indo em direção ao peixe, } \\
\text { poderiam simbolizar a própria hu- } \\
\text { manidade? Já que os mísseis podem } \\
\text { ser vistos indo em direção ao peixe } \\
\text { ou saindo dele, pode-se interpretar } \\
\text { que estes, criados pela humanidade, } \\
\text { também poderiam significar sua } \\
\text { destruição? (ANDRADE; NASCI- } \\
\text { MENTO; GERMANO, 2007). }\end{array}$ & $\begin{array}{l}\text { - Incompatibilidade } \\
\text { da teoria clássica } \\
\text { com o observado } \\
\text { experimentalmente: } \\
\text { seria possível? A ci- } \\
\text { ência já não estaria } \\
\text { pronta e bem defi- } \\
\text { nida? } \\
\text { - Os experimentos } \\
\text { reais dão sempre } \\
\text { certo como o simu- } \\
\text { lador? Retomar } \\
\text { ideia de modelos; } \\
\text { - Significado de } \\
\text { energia quantizada: } \\
\text { o que seriam "paco- } \\
\text { tes" de energia? }\end{array}$ & $\begin{array}{l}\text { - Relacionar, por meio de } \\
\text { uma representação artística } \\
\text { livre (desenho, música, po- } \\
\text { ema, interpretação, etc.), a } \\
\text { música "Quanta" (GIL, } \\
\text { 1997) aos conteúdos vistos } \\
\text { em aula; } \\
\text { - Explorar, matematica- } \\
\text { mente, a relação E = h.f em } \\
\text { diversas situações, como a } \\
\text { energia mínima em fre- } \\
\text { quências definidas do es- } \\
\text { pectro eletromagnético. }\end{array}$ \\
\hline
\end{tabular}

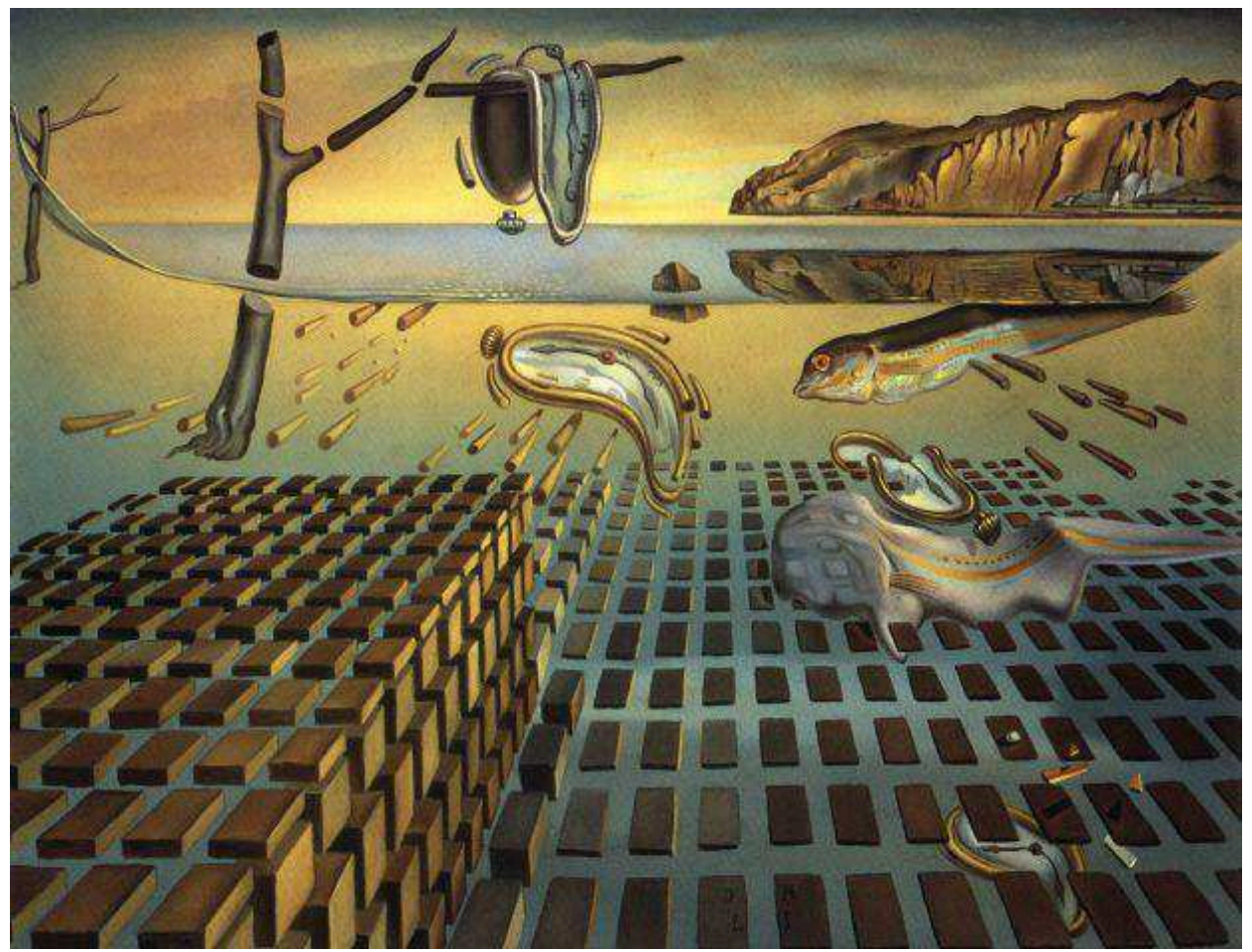

Fig. 2 - A desintegração da persistência da memória. Salvador Dalí (1952-1954). Óleo sobre tela. $25 \times 33$ cm. Museu Dalí de San Petesburgo, Flórida, Fundação Reynold Morse. 
Quadro 4 - Oposição.

\begin{tabular}{|c|c|c|c|}
\hline $\begin{array}{l}\text { QUADRO/ } \\
\text { AULA }\end{array}$ & METODOLOGIA & QUESTÕES DE NdC & $\begin{array}{l}\text { PROPOSTA DE } \\
\text { AVALIAÇÃ̃O }\end{array}$ \\
\hline Oposição & $\begin{array}{l}\text { - Narrativa histórica: luz como onda ele- } \\
\text { tromagnética vs efeito fotoelétrico; } \\
\text { - Simulador: "efeito fotoelétrico" } \\
\text { (PhET): caráter corpuscular da luz; } \\
\text { - Apresentar a proposição de de Broglie } \\
\text { (1924) de que elétrons (até então partí- } \\
\text { culas) também pudessem ter caracterís- } \\
\text { ticas de ondas, estendendo estas ideias a } \\
\text { todo tipo de matéria - dualidade de ma- } \\
\text { téria e radiação (partícula-onda); } \\
\text { - Introdução do quadro: princípio da } \\
\text { complementaridade de Bohr e a duali- } \\
\text { dade partícula-onda - composto por } \\
\text { partículas de dois tipos, azuis e laranjas, } \\
\text { e, apesar da composição dual, a figura } \\
\text { não pode ser separada ou compreendida } \\
\text { apenas por uma das partes, mas pela } \\
\text { complementação de ambas. }\end{array}$ & $\begin{array}{l}\text { - Teoria clássica como ver- } \\
\text { dade absoluta; } \\
\text { - "Partícula ou onda, eis a } \\
\text { questão?” } \\
\text { - É possível ser partícula E } \\
\text { onda ao mesmo tempo? } \\
\text { - Dualidade partícula-onda } \\
\text { por meio do quadro: “a ob- } \\
\text { servação de um impõe limi- } \\
\text { tações à observação do ou- } \\
\text { tro" (ANDRADE; NASCI- } \\
\text { MENTO; GERMANO, } \\
\text { 2007). }\end{array}$ & $\begin{array}{l}\text { - Procurar ou confec- } \\
\text { cionar alguma outra } \\
\text { expressão artística } \\
\text { (pintura, música, qua- } \\
\text { drinho, etc.) que ex- } \\
\text { presse a dualidade } \\
\text { onda-partícula; } \\
\text { - Exercícios sobre } \\
\text { efeito fotoelétrico e } \\
\text { dualidade partícula- } \\
\text { onda. }\end{array}$ \\
\hline
\end{tabular}

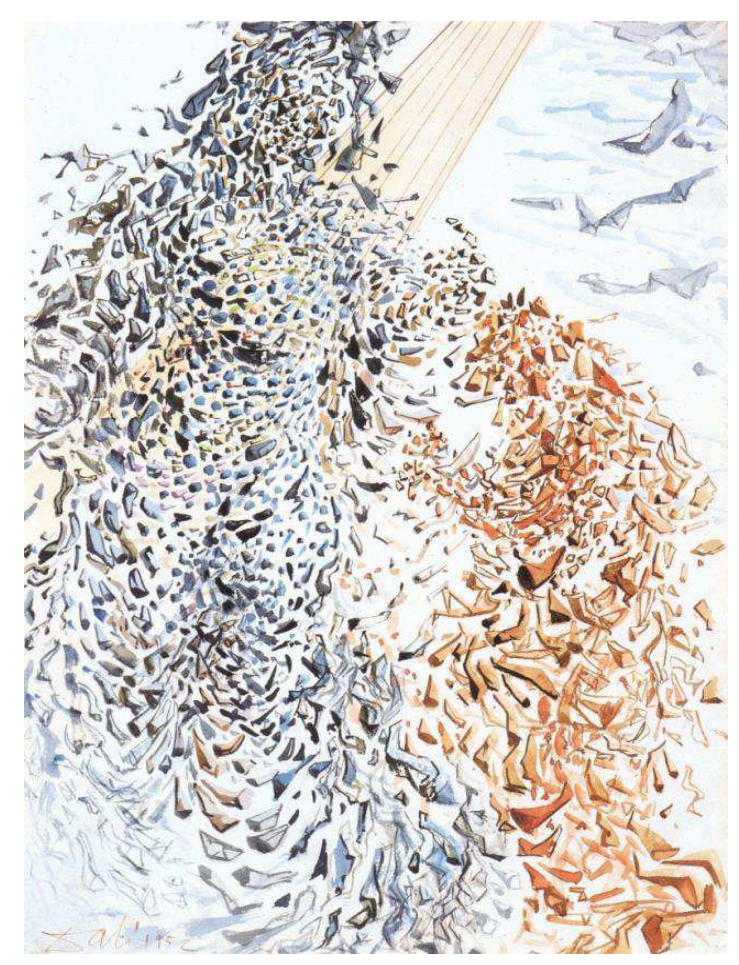

Fig. 3 - Oposição. Salvador Dalí (1952). Aquarela e Tinta. 43,18 x 30,48 cm. 
Quadro 5 - Mercado de escravos com o busto de Voltaire.

\begin{tabular}{|l|l|l|l|}
\hline $\begin{array}{l}\text { QUADRO/ } \\
\text { AULA }\end{array}$ & METODOLOGIA & QUESTÕES DE NdC & PROPOSTA DE AVALIAÇÃo \\
\hline $\begin{array}{l}\text { Mercado } \\
\text { de escra- } \\
\text { vos com o } \\
\text { busto de } \\
\text { Voltaire }\end{array}$ & $\begin{array}{l}\text { - Introdução ao princípio de in- } \\
\text { certeza de Heisenberg; } \\
\text { lacionar princípio de incerteza } \\
\text { com o quadro; }\end{array}$ & $\begin{array}{l}\text { - Interpretação do princí- } \\
\text { pio de incerteza por meio } \\
\text { do quadro: é uma limita- } \\
\text { ção da obra ou da nossa } \\
\text { percepção sobre ela? } \rightarrow \\
\text { Interpretação ontológica } \\
\text { e epistemológica. }\end{array}$ & $\begin{array}{l}\text { - Dissertação sobre a construção } \\
\text { dos conceitos aprendidos até o mo- } \\
\text { mento (modelos atômicos, quanta, } \\
\text { dualidade onda-partícula e princí- } \\
\text { pio da incerteza de Heisenberg), } \\
\text { explicando-os e relacionando-os: } \\
\text { i) com o contexto sócio histórico } \\
\text { em que Dalí estava inserido; }\end{array}$ \\
ii) com o contexto atual; \\
- Exercícios matemáticos sobre o \\
princípio de incerteza.
\end{tabular}

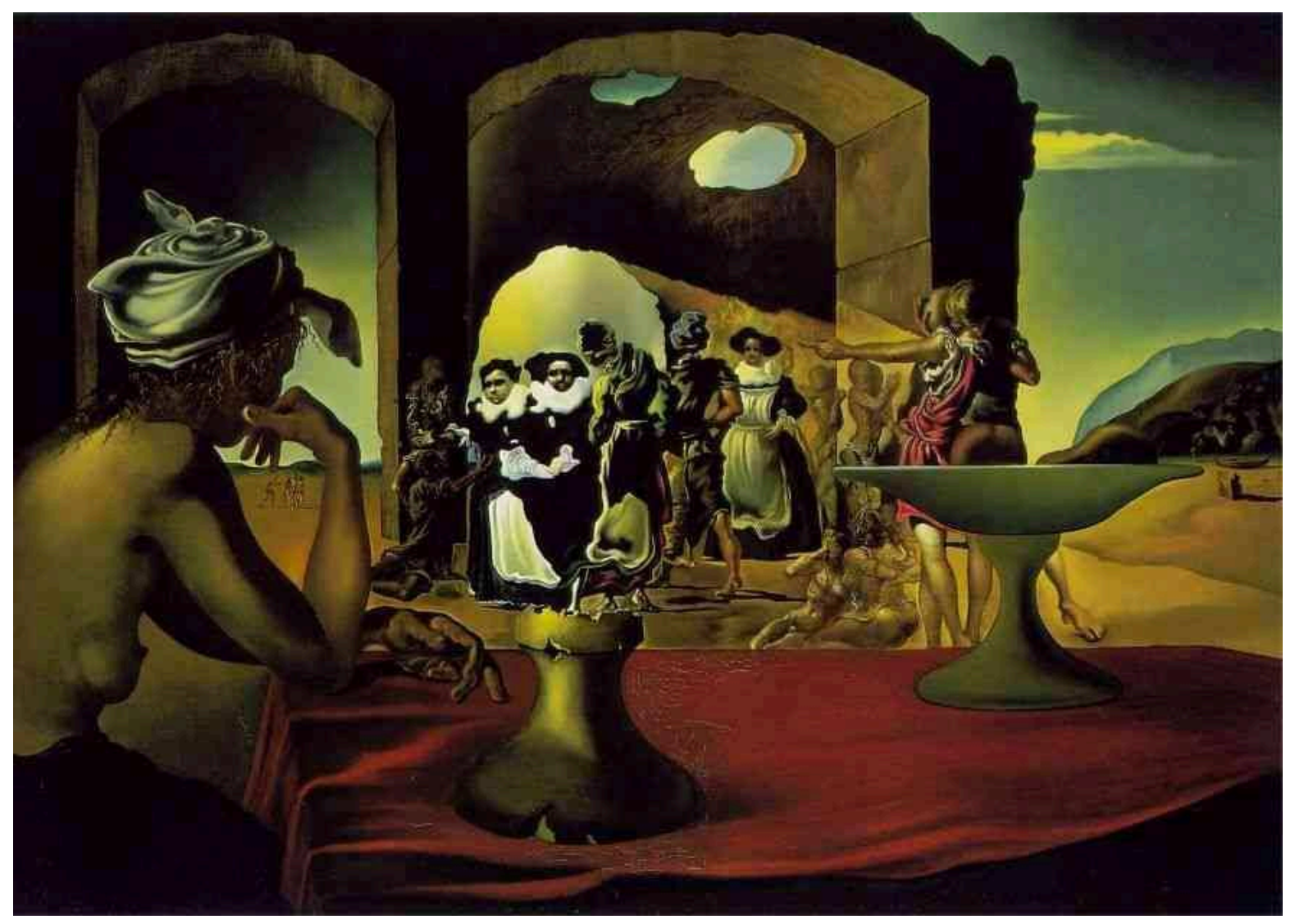

Fig. 4 - Mercado de escravos com o busto de Voltaire. Salvador Dalí (1940). Óleo sobre tela. 46,3 x 65,4 cm. Museu Salvador Dalí, San Petesburg. Flórida. 
Quadro 6 - Referências e sugestões de leituras para professores.

\begin{tabular}{|c|c|}
\hline $\begin{array}{l}\text { Sobre a relação de Salvador Dalí } \\
\text { com a ciência }\end{array}$ & $\begin{array}{l}\text { RUIZ, C. Salvador Dalí and science. Beyond a mere curiosity. Centre } \\
\text { of Dalinian Studies. Gala-Salvador Dalí Foundation. Pasaje a la Ciencia, } \\
2010 \text {. }\end{array}$ \\
\hline $\begin{array}{l}\text { Sobre avaliações e aulas operató- } \\
\text { rias }\end{array}$ & $\begin{array}{l}\text { RONCA, P. A. C.; TERZI, C. do A. A prova operatória. Contribui- } \\
\text { ções da psicologia do desenvolvimento. 5. ed. São Paulo: Dag Gráfica } \\
\text { e Editorial Ltda., } 1993 \text {. }\end{array}$ \\
\hline $\begin{array}{l}\text { Sobre modelos na ciência e uso de } \\
\text { simuladores }\end{array}$ & $\begin{array}{l}\text { BROCKINGTON, G. A Realidade escondida: a dualidade onda-partí- } \\
\text { cula para alunos do Ensino Médio. 2005. Dissertação (Mestrado) - } \\
\text { IF/FE-USP, São Paulo. }\end{array}$ \\
\hline $\begin{array}{l}\text { Sobre interpretação da radiação } \\
\text { de corpo negro }\end{array}$ & $\begin{array}{l}\text { MENEZES, L. C. A intimidade quântica. In: MENEZES, L. C. (Org). A } \\
\text { Matéria: Uma Aventura do Espírito. São Paulo: Livraria da Física, } \\
\text { 2005. p. 141-182. } \\
\text { EINSTEIN, A., INFELD, L. Quanta. In: EINSTEIN, A., INFELD, L. } \\
\text { (Org.) A Evolução da Física. Rio de Janeiro: Jorge Zahar Ed.2008. p. } \\
\text { 207-241. }\end{array}$ \\
\hline Sobre visões distorcidas na ciência & $\begin{array}{l}\text { GIL-PÉREZ, D. et al. Para uma imagem não deformada do trabalho ci- } \\
\text { entífico. Ciência \& Educação, v. 7, n. 2, p. 125-153, } 2001 .\end{array}$ \\
\hline $\begin{array}{l}\text { Sobre historiografia e pseudo-his- } \\
\text { tória }\end{array}$ & $\begin{array}{l}\text { FORATO, T. C. M.; PIETROCOLA, M.; MARTINS, R. A. Historiogra- } \\
\text { fia e natureza da ciência na sala de aula. Caderno Brasileiro de Ensino } \\
\text { de Física, v. 28, n. 1, p. 27-59, } 2011 . \\
\text { MARTINS, R. de A. Como não escrever sobre história da física - um } \\
\text { manifesto historiográfico. Revista Brasileira de Ensino de Física, v. } \\
\text { 23, n. 1, p. 113-129, } 2001 .\end{array}$ \\
\hline $\begin{array}{l}\text { Sobre história da Mecânica } \\
\text { Quântica e alguns de seus perso- } \\
\text { nagens }\end{array}$ & $\begin{array}{l}\text { ABDALLA, M. C. B. Niels Bohr: o arquiteto da mecânica quântica. } \\
\text { Gênios da Ciência Quânticos. Scientific American Brasil, ed. 13, p. } \\
\text { 32-43, } 2006 . \\
\text { ANDRADE, R. R. D.; NASCIMENTO, R. S.; GERMANO, M.G. In- } \\
\text { fluências da Física Moderna na Obra de Salvador Dalí. Caderno Brasi- } \\
\text { leiro de Ensino de Física, v. 24, n. 3, p. 400-423, dez. } 2007 . \\
\text { HEISENBERG, W. K. A parte e o todo: encontros e conversas sobre } \\
\text { física, filosofia, religião e política. Rio de Janeiro: Contraponto, } 1996 . \\
\text { MARTINS, R. A. O nascimento de uma nova física. Gênios da Ciência } \\
\text { Quânticos. Scientific American Brasil, ed. 13, p. 6-13, } 2006 . \\
\text { ROSA, P. S.; MARTINS, R. A. Louis de Broglie. Gênios da Ciência } \\
\text { Quânticos. Scientific American Brasil, ed. 13, p. 44-55, } 2006 .\end{array}$ \\
\hline
\end{tabular}




\section{Algumas considerações}

Como o nível de abstração exigido no ensino de FMC é alto, se faz necessário reconsiderar os pressupostos teóricos, abordagens e metodologias, minimizando dificuldades na sua inserção (BROCKINGTON, 2005). Embora a utilização de temas de FMC apresente diversos problemas em sua adaptação para o ensino médio, como, por exemplo, as tão fartamente registradas dificuldades com as bases matemáticas, ou a dificuldade de executar experimentos nos laboratórios escolares, ou ainda a não existência de experimentos a nível macroscópico que ilustrem os conceitos apresentados, esses problemas podem ser minimizados por meio do uso dessas novas metodologias, uma vez que a proposta trabalha os mesmos conceitos por meio de uma nova abordagem. Abraçar as relações entre física e arte permite que os conceitos sejam explicitados por meio de analogias advindas da ponte comum entre essas duas culturas.

Ao optarmos por aproximar duas diferentes áreas de conhecimento, inicialmente vistas caminhando em direções distintas, mas de natureza semelhante, proporcionamos aos estudantes uma visão mais ampla sobre o mundo à nossa volta. Repensar metodologias, adicionando elementos culturais ao mundo da física se faz cada vez mais necessário, pois parece ressignificála ao proporcionar inovações curriculares que tendem a re-humanizar os conhecimentos físicos e, por isso mesmo, favorecem o diálogo com o aluno e com o seu universo.

Acreditamos, no entanto, que apenas a utilização de elementos artísticos para a abordagem de temas de FMC de maneira fundamentalmente conceitual possa levar a deformações sobre a essência da própria física, uma vez que a matematização se constitui como um de seus estruturantes (PIETROCOLA, 2002). Dessa forma, unir ambos os eixos, conceitual e matemático, aliados às analogias advindas das obras artísticas, pode proporcionar níveis mais profundos de compreensão sobre os temas de mecânica quântica apresentados, bem como da natureza da física - essencialmente humana.

Como desdobramento, a proposta será implementada e avaliada em ambientes reais de sala de aula em escolas do estado de São Paulo. As possíveis dificuldades, a nosso ver, residem na interpretação probabilística, inerente à física quântica, em que um mesmo objeto pode ser interpretado e analisado a partir de mais de uma maneira, diferindo do pensamento determinista da física clássica.

É preciso que existam mais trabalhos que integrem outras concepções às escassas metodologias de ensino de mecânica quântica, uma vez que propostas que envolvem conteúdos de FMC na educação básica se apresentam em pequeno número quando comparadas às outras áreas do ensino de física.

\section{Referências}

ACEVEDO-DÍAS, J. A.; GARCÍA-CARMONA, A. Algo antiguo, algo nuevo, algo restado. Tendencias sobre la naturaleza de la ciencia en la educación científica. Revista Eureka sobre Enseñanza y Divulgación de las Ciencias, v. 13, n. 1, p. 3-19, 2016. 
ALCANTARA, M. C., JARDIM, W. T. A utilização da HFC no ensino de física a partir de representações artísticas. In: CONFERENCIA LATINOAMERICANA DEL INTERNATIONAL, HISTORY AND PHILOSOPHY OF SCIENCE TEACHING, III, 2014, Santiago, Chile. Atas...

ALLCHIN, D.; ANDERSEN, H.; NIELSEN; K. Complementary approaches to teaching nature of science: Integrating student Inquiry, Historical Cases, and Comtemporary Cases in the Classroom Practice. Science Education, v. 98, n. 3, p. 461-486, 2014.

ALFONSO-GOLDFARB, A. M. O que é história da ciência. São Paulo: Brasiliense, 1994.

ANDRADE, R. R. D., NASCIMENTO, R. S., GERMANO, M. G. Influências da Física Moderna na Obra de Salvador Dalí. Caderno Brasileiro de Ensino de Física, v. 24, n. 3, p. 400423, dez. 2007.

ANDRÉ, M. E. D. A.; LUDKE, M. Pesquisa em educação: abordagens qualitativas. São Paulo, E.P.U., 1986. 99p.

BAGDONAS, A. Controvérsias envolvendo a natureza da ciência em sequências didáticas sobre cosmologia. 2015. Tese (Doutorado) - Instituto de Física, Instituto de Química, Instituto de Biociências e Faculdade de Educação da Universidade de São Paulo.

BRASIL. Ministério da Educação. Parâmetros Curriculares Nacionais (Ensino Médio). Secretaria de Educação Média e Tecnológica. Brasília: MEC, 2000.

. Secretaria de Educação Média: Parâmetros Curriculares Nacionais + - Ensino Médio: Orientações Educacionais Complementares aos Parâmetros Curriculares Nacionais. Física. Secretaria de Educação Média. Brasília: MEC - SEMTEC, 2002. 122p

BROCKINGTON, G. A Realidade escondida: a dualidade onda-partícula para alunos do Ensino Médio. 2005. Dissertação (Mestrado) - IF/FE-USP, São Paulo.

DALÍ, S. Anti-matter manifesto. Carstairs Gallery, New York, December 1958 - January 1959.

DE BROGlie, L.; SertillangeS, A. D. Para Além da Ciência. Porto: Livraria Tavares Martins, 1955. $302 \mathrm{p}$.

DEMO, P. Educar pela pesquisa. Campinas: Autores Associados, 1996.

FORATO, T. C. M.; PIETROCOLA, M.; MARTINS, R. A. Historiografia e natureza da ciência na sala de aula. Caderno Brasileiro de Ensino de Física, v. 28, n. 1, p. 27-59, 2011.

GIL, G. Quanta. CD Quanta, Warner Music, Manaus, 1997. 
GIL-PÉREZ, D. et al. Para uma imagem não deformada do trabalho científico. Ciência \& Educação, v. 7, n. 2, p. 125-153, 2001.

HEGEL, G.W. F. Curso de estética: o belo na arte. São Paulo: Martins Fontes, 1996.

KANT, I. Crítica da faculdade do juízo. Rio de Janeiro: Forense Universitária, 1993.

LOPES, C. V. M.; MARTINS, R. A. J. J. Thomson e o uso de analogias para explicar os modelos atômicos: o 'pudim de passas' nos livros texto. In: ENCONTRO NACIONAL DE PESQUISA EM ENSINO DE CIÊNCIAS, VII, 2000, Florianópolis. Anais...

MARTINS, A. F. P. História e filosofia da ciência no ensino: há muitas pedras nesse caminho. Caderno Brasileiro de Ensino de Física, v. 24, n. 1, p. 112-131, 2007.

MARTINS, R. A. Como não escrever sobre história da física - um manifesto historiográfico. Revista Brasileira de Ensino de Física, v. 23, n. 1, p. 113-129, 2001.

MATTHEWS, M. Science teaching: The Role of History and Philosophy of Science. London: Routledge, 1994.

MENEZES, L. C. A intimidade quântica. In: MENEZES, L. C. (Org). A Matéria: Uma Aventura do Espírito. São Paulo: Livraria da Física, 2005. p. 141-182.

MOREIRA, M. A. Grandes desafios para o Ensino da Física na Educação Contemporânea. In: CONFERÊNCIA INTERAMERICANA SOBRE ENSEÑANZA DE LA FÍSICA, XI, 2013, Guayaquil, Equador.

MOURA, B. A. Formação crítico-transformadora de professores de Física: uma proposta a partir da História da Ciência, 2012. Tese (Doutorado em Ensino e Física) - Faculdade de Educação, IF, IQ, IB, FE Universidade de São Paulo.

PIETROCOLA, M. A matemática como estruturante do conhecimento físico. Caderno Catarinense de Ensino de Física, v. 19, n. 1, p. 89-109, ago. 2002.

PIMENTA, S. G.; GHEDIN, E. (Orgs). Professor Reflexivo no Brasil: gênese e crítica de um contexto. 7. ed. São Paulo: Cortez Editora, 2012.

PIRES, F. F.; SILVA, J. A. Estética e simetria no ensino de física: uma proposta para o ensino de mecânica. In: ENCONTRO NACIONAL DE PESQUISA EM ENSINO DE CIÊNCIAS, X, 2015, Águas de Lindoia. Anais...

REIS, J. C.; GUERRA, A.; BRAGA, M. Ciência e arte, relações improváveis? História, ciências, saúde, Manguinhos, v. 13, suplemento, p. 71-87, 2006.

RONCA, P. A. C.; TERZI, C. do A. A prova operatória. Contribuições da psicologia do desenvolvimento. $5^{\text {a }}$. Ed. São Paulo: Dag Gráfica e Editorial Ltda, 1993. 
RUIZ, C. Salvador Dalí and science. Beyond a mere curiosity. Centre of Dalinian Studies. Gala-Salvador Dalí Foundation. Pasaje a la Ciencia, 2010.

SEE-SP. Currículo do Estado de São Paulo: Ciências da Natureza e suas tecnologias. Secretaria da Educação. 1. ed. atual. São Paulo: SE, 2014-2017.

SHAKESPEARE, W. Hamlet. Editora Abril, 1976.

SNOW, C. P. The two cultures. Cambridge: Cambridge University Press, 1993.

UNIVERSIDADE DO COLORADO (Org.). PhET Interactive Simulations. Efeito fotoelétrico. Disponível em: <https://phet.colorado.edu/pt_BR/simulation/photoelectric $>$. Acesso em: 29 nov. 2015.

PhET Interactive Simulations. Radiação do Corpo Negro. Disponível em: $<$ https://phet.colorado.edu/pt/simulation/blackbody-spectrum>. Acesso em: 29 nov. 2015.

ZANETIC, J. Física também é cultura. 1989. 252 p. Tese (Doutorado) - USP, São Paulo.

Física e arte: uma ponte entre duas culturas. Pro-Posições, v. 17, n. 1 (49), p. 39-57, jan./abr. 2006. 